\title{
EDUCAÇÃO SUPERIOR NO INTERIOR DO PARANÁ: O PROCESSO DE CONSTITUIÇÃO DA FACULDADE DE FILOSOFIA, CIÊNCIAS E LETRAS DE GUARAPUAVA-FAFIG (1960-1970)
}

\author{
Mari Lucia do Amaral ${ }^{1}$ \\ Carlos Herold Junior ${ }^{2}$
}

\section{RESUMO}

Este estudo tem como objetivo analisar o processo de criação da Faculdade de Filosofia, Ciências e Letras de Guarapuava a (FAFIG), no interior do Estado do Paraná. Como fontes primárias de pesquisa nós utilizamos jornais da época, documentos da instituição, e, entrevistas com ex-alunos, ex-docentes, e membros da sociedade, que participaram da instalação da Faculdade. Como conclusão, nós observamos que a criação da FAFIG ocorreu inserida no processo de discussão sobre o ensino superior que acontecia no Brasil nas décadas de 1960 e 1970, mobilizando setores políticos e econômicos da cidade para superar a falta de professores para a educação básica da cidade.

Palavras-chave: educação; ensino superior; história, Guarapuava

\section{HIGHER EDUCATION IN INLAND OF PARANÁ: THE PROCESS OF THE CONSTITUTION OF FACULDADE DE FILOSOFIA, CIÊNCIAS E LETRAS DE GUARAPUAVA-FAFIG (1960-1970)}

\begin{abstract}
This study aims to analyze the process of creation of the Faculty of Philosophy, Sciences and Letters of the Guarapuava (FAFIG), in the State of Paraná. As primary research sources we use newspapers of the time, the institution's documents, and interviews with former students, former teachers, and members of society, who participated in the installation of the Faculty. In conclusion, we observed that the creation of FAFIG was inserted into the discussion of higher education that occurred in Brazil in the 1960s and 1970s process, mobilizing political and economic sectors of the city to overcome the shortage of teachers for basic education city
\end{abstract}

Keywords: education, higher education, history, Guarapuava

\section{INTRODUÇÃO}

Este estudo analisa as relações entre trabalho e educação, focalizando-as a partir da história de uma instituição de ensino superior: a Faculdade de Filosofia Ciências e Letras de Guarapuava FAFIG, fundada em 1970. A intenção maior da pesquisa é construir subsídios para entendermos as maneiras como as forças sociais envolvidas na criação da FAFIG pensaram a importância da Instituição para a realidade, situando esse conjunto de reflexões e de ações no âmbito do movimento nacional de expansão das universidades e faculdades. Assumimos que esse processo que ocorreu em Guarapuava esteve conectado ao movimento maior de expansão das instituições de ensino superior do país. Para 
demonstrar isso, foi necessário situar o objeto de análise - a Instituição de Ensino Superior FAFIG - em seus condicionantes internos e externos, relacionando-a às transformações do modo de produção capitalista.

No bojo das transformações nos processos de produção no decorrer do século XX e seus reflexos nas relações sociais e econômicas existentes no Estado do Paraná, criaram-se possibilidades e as dificuldades históricas e sociais vivenciadas por Guarapuava nas décadas de 1960 e 1970, levando que a sociedade guarapuavana à discução para implementar o ensino superior na cidade. Esses esforços são importantes para entendermos como os processos educativos evoluíram na região de Guarapuava. É necessário, também, olhar o processo por seu condicionante interno, afinal a educação aparecia na pauta das discussões dos assuntos primordiais na cidade desde décadas anteriores de 1930 a 1960 , como foi possível constatar em um trabalho anterior:

[...] apesar dos problemas estruturais da educação, a sociedade guarapuavana nos seus processos de transformações sociais atribuiu à educação grande valor, que ora era concebida como um progresso existente, ora como parâmetro a ser acompanhado por setores da vida econômica e social da cidade. (AMARAL e HEROLD JR, 2010, p.2)

A FAFIG nascia em meio a transformações nas estruturas econômicas, políticas e culturais da cidade. A instituição passa a ter um significado especial para os guarapuavanos. A sociedade política e civil participaram na convergência para $o$ estabelecimento do ensino superior na cidade. Guarapuava passa ser a uma referência no ensino superior para o centro-oeste, o sudoeste, e toda região oeste, pois era a única instituição de ensino superior estadual, naquela época, lá presente. Isso levou a FAFIG a ter alunos oriundos de todas essas regiões e outras ainda.

A pesquisa que deu origem a este trabalhose apoiou em livros, teses e dissertações que tratam do tema. Do ponto de vista documental, ela baseou-se, principalmente, em jornais locais do período e documentos da instituição. O Jornal Folha do Oeste circulou na cidade de 1937 até metade da década de 1980. Scheubauer e Araújo (2007, p.5) endossam a importância de se fazer o uso dessas fontes: "se a educação é uma prática social que se estrutura a partir do que é veiculado pela cultura, a imprensa tem seu lugar na educação dos homens em sociedade". Além dos documentos, faremos o uso de entrevistas que ajudarão a reconstruir o processo de criação da faculdade e, igualmente, fornecerão importantes subsídios empíricos para o estudo. Baseamos-nos para essa fase da pesquisa, nos estudos de Paul Thompson (1992), que destaca a importância e os cuidados que se requer com esse tipo de fonte: "a história oral pode dar grande contribuição para o resgate da memória nacional, mostrando-se um método bastante promissor para a realização de pesquisa em diferentes áreas". (THOMPSON, 1992, p. 17).

Todo esse conjunto de fontes primárias e secundárias será analisado através do crivo teórico-metodológico do materialismo histórico e dialético. Nesse sentido, procuramos realizar a análise de conjuntura da gênese da FAFIG, inserida no bojo, das relações que constituem a sociedade capitalista. Entendemos o processo como fruto dos movimentos e das mudanças ocorridas e como uma amostragem das diferentes determinações do processo de produção capitalista na região:

Essa concepção de história consiste, portanto, em desenvolver o processo real de produção a partir da produção material da vida imediata e em conceber a forma de intercâmbio conectada a esse modo de produção e por ele engendrada, quer dizer, a sociedade civil em seus diferentes 
estágios, como o fundamento de toda a história, tanto a apresentando em sua ação como Estado como explicando a partir dela o conjunto das diferentes criações teóricas e formas da consciência - religião, filosofia, moral, etc. - e em seguir o seu processo de nascimento a partir dessas criações, o que então torna possível, naturalmente, que a coisa seja apresentada em sua totalidade (assim como a ação recíproca entre esses diferentes aspectos) (MARX e ENGELS, 2007, p. 42).

O movimento de transformação do modo de produção vem sempre acompanhado de crises de produção na qual se revela o embate entre as classes sociais. Nas instituições de ensino superior, o embate pode ser interpretado, ora como uma forma de manutenção da ordem social em que impera o capital, ora por um posicionamento que busca a transformação da sociedade capitalista.

\section{Diferentes entendimentos sobre o processo de criação da Faculdade de Filosofia Ciências e Letras de Guarapuava FAFIG}

Guarapuava, no período destacado, encontrava-se entre necessidade e ao mesmo tempo um sonho idealizado da faculdade de agronomia e veterinária, ressentindo-se da formação de professores para a região de Guarapuava. Ao consultar as fontes primárias de pesquisa, percebemos que a cidade de Guarapuava pleiteava o ensino superior desde a década de 1950. A partir dessa década esse discurso vai ganhando cada vez mais força No estudo de Silva (2008, p. 137,138), vemos que Lustosa de Oliveira apresentou à Assembleia Legislativa do Paraná um projeto no qual aparece a vontade de se fazer em Guarapuava uma Escola Superior de Agronomia e Veterinária. Todavia, o projeto e as emendas orçamentárias ou constitucionais que ele apresentou, no sentido de viabilizar essa pauta, foram todos rejeitados pela Assembleia.

Na pesquisa de Fillos (2008, p. 6,7), constata-se que, com a expansão do ensino secundário, havia a falta de docentes, profissionais de outras áreas lecionassem as matérias da grade curricular nos ginásios e colégios. A escassez de professores habilitados para os cursos ginasial e colegial era um sério problema em todo o Brasil. Se tinham as escolas, era necessário o treinamento dos docentes para nelas atuarem, tendo em vista que a maioria dos professores então atuantes era leiga.

Com essa necessidade posta, o governo federal, na época, lançou a CADES(Campanha de Aperfeiçoamento e Difusão do Ensino Secundário), pelo Decreto $\mathrm{n}^{\circ}$ 34.638, de 14 de novembro de 1953. Pinto (2008) realizou estudo sobre a CADES e sua análise demonstra o panorama do problema:

O ensino superior era incipiente: em 1952, havia apenas 514 unidades com 56.049 matrículas. O número de faculdades de filosofia, cujos cursos seriam, como pretendia a Reforma Francisco Campos, obrigatórios "para todos quantos se proponham ao ensino secundário nos ginásios oficiais e equiparados", não atendia às necessidades do momento. Acresce a isso, $o$ fato dessas faculdades se localizarem nas capitais e nas grandes cidades das regiões mais desenvolvidas, o que impedia que os professores do interior $[. .$.$] as freqüentassem. Assim sendo, o corpo docente do ensino$ secundário era basicamente constituído por profissionais liberais (advogados, farmacêuticos, médicos, engenheiros), padres e normalistas (PINTO, 2008, p.3). 
O CADES foi uma tentativa de difundir e elevar o padrão do ensino secundário e adequar esse nível de ensino às necessidades do momento. Nesse sentido, foram realizados vários cursos de treinamento para professores, diretores, inspetores de ensino, secretários de escolas, além de divulgar publicações referentes ao ensino secundário. Nesses cursos, eram ministrados os conteúdos específicos das disciplinas que os professores iriam lecionar, ou que já estavam lecionando, e, também, as disciplinas pedagógicas e demais treinamentos para a escola. Tais cursos eram realizados nos períodos de férias, no mês janeiro, ou de julho.

A partir de 1956, a CADES, passou a promover, nas inspetorias seccionais do ensino secundário espalhadas por todo o país, cursos intensivos de preparação aos exames de suficiência que, de acordo com a Lei $\mathrm{n}^{\circ}$ 2.430, de 19 de fevereiro de 1955, conferiam aos aprovados o registro de professor do ensino secundário e o direito de lecionar onde não houvesse disponibilidade de licenciados em faculdades de filosofia.

Nos meses de janeiro e fevereiro de 1954, realizaram-se os primeiros cursos de orientação para os professores inscritos em exame de suficiência. Esses cursos eram destinados a professores de português, inglês, matemática, ciências naturais do $1^{\circ}$ ciclo do ensino secundário e aconteceram em várias cidades brasileiras: Recife, Salvador, Nova Friburgo, Porto Alegre, Curitiba e Belo Horizonte.

Por essa época, Guarapuava começava a ganhar contornos de uma cidade moderna, visto que a movimentação do comércio da madeira trouxe um fluxo de capital para cidade que ainda possuía contornos de uma cidade colonial. Por conta disso, os discursos em torno da modernização dos demais segmentos da cidade ganharam força, dentre eles, a educação conforme (AMARAL E HEROLD JR 2010).

A partir de 1955, os professores de Guarapuava iam fazer exames de suficiência em Curitiba para lecionarem no ensino secundário, que ainda era pouco consistente na cidade e a área agrícola, por sua vez abrangente na região como um todo, apenas ganhava uma escola rural com curso inicial de nível primário e noções elementares para agricultura, somente no ano de 1960 essa mesma escola rural é elevada ao nível de Escola Agrícola de Nível Médio, pelo decreto $\mathrm{n}^{\circ}$. 31.657/60, publicado no diário oficial $\mathrm{n}^{\circ}$. 144/60 (SANTOS E SHREIBER, 2011) Em Guarapuava e região, nas décadas citadas, quase todos os professores eram professores leigos, eles realizavam os cursos, e, os treinamentos oferecidos pelo governo e para poderem lecionar faziam os exames de suficiência. Por conta dessa situação, o assunto de uma faculdade de filosofia em Guarapuava estava presente entre esses docentes e as reivindicações em torno dessa possibilidade começaram a aumentar.

O Jornal Folha do Oeste, no ano de 1962 ( ${ }^{\circ} 1292$, de 18 de março) traz uma matéria destacando a importância das instituições de nível superior e as preocupações com esse ensino no interior do Estado. Lorival Santos Lima destaca, na primeira página, a "Responsabilidade Universitária", salientando o que estava acontecendo no interior: "As faculdades estaduais, onde se ensaia, isola e improvisadamente uma estrutura universitária, está a exigir tudo" (FOLHA DO OESTE, 1962, p.1 e 8). O redator endossa a necessidade de maior estrutura para as faculdades existentes e mesmo o desejo de querer uma universidade no interior.

O mesmo redator, em outro exemplar, com o título da matéria: "Alfabetização e Culturalização: A ignorância desconhece que ignora", deixa clara a sua indignação com a situação do ensino superior nacional, na capital e no interior do estado, bem como a sua insatisfação com a situação da educação nas demais modalidades de ensino. Em tom de protesto e ao mesmo tempo buscando elogiar as iniciativas do governo do estado, ele destaca: “... se fez ensaio promissor com a Universidade Volante” (FOLHA DO OESTE, 
25/03,1962 p. 1), referindo-se à iniciativa da Universidade Federal do Paraná que, na década de 1960, lançou o programa universitário da Universidade Volante. E ao mesmo tempo explana sobre o problema da formação universitária:

O nosso ensino médio e universitário não tem correspondido ao nível de preparação necessária às elites, responsáveis pela condução das massas nacionais, por sua vez carentes de melhor índice de alfabetização. Reformas de ensino tem havido e muitas [...] A eloquência e a retórica, após o brilha com que inspirou poetas, romancistas e oradores nunca deixou de causar o desvio de nossas preocupações intelectuais, através de quatrocentos anos de história, em que a escola veio muito tarde pelos naturais interesses reinóis.[...] ficamos como que atrasados no tempo, com as mesmas predileções intelectuais, as quais nos tem afastado da cultura séria, só capaz de fundamentar-se na ciência e na filosofia. [...] A alfabetização, pois é campanha de grande significação popular, para a urgente elevação de nosso povo, mas só será completa e eficiente, em seus objetivos finais, com a culturalização de nossos alfabetizados, mormente quando estes constituem ou pretende ser, as nossas elites formadoras e dirigentes, educativas e políticas. (FOLHA DO OESTE, $25 / 03, n^{\circ} 1293,1962$, p.1 e 8 )

A matéria chama à atenção pela forma como trata a questão da educação, afirmando a gravidade do problema. Claro que o redator alerta para uma crítica da formação dos políticos e expressa a reivindicação pela melhora, principalmente, da educação da elite, que deveria ser a responsável por conduzir a grande massa. Isso, sem deixar de pontuar que o problema educacional afligia à educação de todas as classes sociais. De qualquer modo, o discurso do redator exprime, claramente, a naturalização da divisão da sociedade em classes e a divisão estrutural da educação como um traço "lógico"..

Lorival Santos Lima na sua coluna, continua nas edições seguintes do Folha do Oeste, presentes nos segmentos desse mesmo ano de 1962. Por meio de seus artigos que vemos circular em Guarapuava ponderações sobre a crise universitária no Brasil nessa época. Nesse sentido, chama-nos atenção a forma como o redator descreve e enuncia os problemas:

Ante a criação de mais uma universidade - a Universidade do Norte, segundo a declaração oficial, na instalação da Universidade Volante, em Londrina. [...] A proliferação de escolas universitárias isoladas, com a hipertrofia de especialidades [...] é mal para a autêntica missão da universidade. [...] Pois a universidade deve ser um todo - o cérebro que comanda o corpo e os membros. [...] Urge que a demagógica fase de mieneirismo ${ }^{3}$, entre nós, seja superada pela estruturação e unidade do ensino superior estadual. Para que este logo chegue ao nível da universidade em seu sentido integral de transmissão da cultura, profissionalismo e técnica, estudos e pesquisa, bem como expansão sistemática de seu ensino. (FOLHA DO OESTE, N 1295,15/04,1962, p.8)

Por esse início da década de 1960, havia discussões fortes em torno da interiorização do ensino superior no Paraná, Sobretudo, na direção das três maiores cidades do interior do Estado, devido à sua maior força política e econômica (SHEEN, 2000). A coluna apresentada pelo redator trouxe discussões advindas daquele período de crise do ensino superior no Brasil e também as necessidades de se fundar, em Guarapuava, uma 
instituição desse nível. As discussões proporcionadas por Lorival Santos Lima eram veiculadas em toda a região: Jornal da Manhã (Ponta Grossa) Folha do Oeste e Rádio Difusora (Guarapuava) e Tribuna dos Municípios (Irati).

Em Curitiba, foi criado o Centro Estudantil Guarapuavano (CEG) em primeiro de maio de 1959, para ajudar os jovens guarapuavanos na capital do Estado em sua formação em nível superior. Na edição do jornal Folha do Oeste ( $\left.N^{\circ} 311\right)$, de dez de abril de 1960, são anunciadas as comemorações de um ano de existência do Centro, jogos, discussões literárias, jantar e baile. O CEG teve peso nas discussões para a instituição da faculdade na cidade de Guarapuava. Conforme o relato de Marcondes (2010, p. 417), em um dos encontros do Centro Estudantil estava presente o Sr. Moacyr Júlio Silvestri, político de grande influência local, que foi convidado pelos membros do CEG a abraçar a causa em questão. No evento, ele assumiu o compromisso de lutar pela faculdade, o que também foi feito pela comunidade e a sociedade guarapuavana, no decorrer da década de 1960.

Em entrevista concedida no dia 03/09/2013, o Sr. Alcides Ragazzi, ex-sacerdote, na época, ainda era Padre Egídio Ragassi, da congregação dos padres salvatorianos, esteve envolvido, diretamente, com o processo de construção da Faculdade. Em seu relato ele afirma que veio a Guarapuava para fundar uma paróquia e prestar assistência espiritual aos funcionários da Lutcher Brown S/A, fábrica de celulose no município Candói, na comunidade do Salto Segredo. No local destinado à sede da paróquia em Guarapuava, tinha também, a missão de organizar a construção de um seminário que funcionaria em regime de internato. Esse terreno estava no nome da Mitra Diocesana de Ponta Grossa. Era um terreno grande e sem construção alguma, foi preciso fazer uma primeira construção para a igreja matriz e para a casa paroquial.

O Sr. Ragazzi relata que havia interesse dos padres da congregação salvatoriana em construir um colégio de nível secundário e ele foi o responsável pelo começo de tudo. $\mathrm{O}$ fato é que o colégio, em regime de internato, não foi instalado, mas a edificação do prédio serviria para abrigar uma futura faculdade na cidade de Guarapuava. Nesse ponto uniramse, a comunidade eclesiástica com os representantes políticos e os demais representantes da sociedade guarapuavana como o Lions Clube de Guarapuava, a imprensa local e o professorado.

Em 1966, foi organizada uma equipe de trabalho sob a orientação do, então, padre Egídio que realizou um trabalho de sondagem "uma espécie de estatística" para comprovar que Guarapuava possuía todas as condições de abrigar e manter uma instituição de ensino superior. Ele conversou com representantes de todos os setores da cidade, como os representantes da comunidade, os políticos locais e a comunidade escolar, secretarias de educação e percebeu com mais clareza as necessidades locais.

Nessa época, intensificaram-se campanhas em Guarapuava por uma Faculdade. O Lions Clube da cidade passou a publicar várias notas no semanário local, pedindo a Faculdade, destacando a reivindicação em letras de caixa alta "O Centro Oeste precisa da FACULDADE DE FILOSOFIA EM GUARAPUAVA" (FOLHA DO OESTE, 1967, p. 2). Assim se multiplicaram as campanhas em prol da faculdade com matérias falando à respeito dessa necessidade.

Mas uma vez nos ocorreu a união do povo guarapuavano pró-construção e aparelhamento de um prédio para funcionamento da ansiosamente esperada FACULDADE de Guarapuava. Dádiva das mais régias e significativas com que a atual geração dominante guarapuavana se imortalizaria no consenso de seus pósteros e de sua juventude atual que de livros a tira-colo. [...] Portanto deve o nobre povo meditar bem sobre sua responsabilidade e dever de coesão em torno da urgente 
concretização de uma ou mais FACULDADES em Guarapuava, que para bem funcionar exige prédio e instalações adequadas que estão ao alcance do vosso econômico. (FOLHA DO OESTE, 1968, p.1) .

O mesmo redator persiste no argumento, pedindo a união de toda a cidade na campanha em prol Faculdade:

Oportuna seria pois, a formação de uma Comissão de Pais e Estudantes
guarapuavanos - equidistante de cor política para desfigurá-la à qual
devem ser convidados a se integrar os Poderes Judiciário, Executivo,
Legislativo, Clero, Imprensa, Rádio, Associações de Classe e Profissões
Liberais, para ir a Curitiba e lá com o Secretário deputado João de Mattos
Leão, com o prefeito Nivaldo Kruger, deputado Moacir Silvestre, com o
Presidente da Câmara Dr. João Serpa Arruda e Vereadores, com nosso
Bispo, com representantes da Associação Industrial e Comercial de
Guarapuava, com o comandante da briosa Unidade do Exército Nacional
aqui sediada, com nossos médicos, advogados, dentistas, agrônomos,
arquitetos, veterinários, professores, Lions, Rotary, Bancários, Radialistas
e Jornalistas, homens que tiveram a ventura de estudar e bem sabem a
importância que isso representa para a Civilização de uma comunidade.
(FOLHA DO OESTE, 1968, p.1)

Datado no mesmo jornal Folha do Oeste do corrente ano de 1968, o destaque dado a uma passeata de estudantes com seus cartazes que pressionavam as autoridades à construção da instituição. As justificativas da solicitação davam conta de que aqueles que não possuíam recursos para ir para outros lugares estudar, ficava sem condições de ter formação de nível superior. A passeata reivindicando a faculdade para Guarapuava abrangeu a principal rua da cidade com concentração em torno do terminal rodoviário, seguida por pedestres, um carro com alto falante e outros automóveis com faixas e cartazes pela rua principal. Nos cartazes estava escrito também em caixa alta: "QUEREMOS UMA FACULDADE!", "PROGRESSO É CULTURA", "AJUDEM AQUI AOS QUE NÃO TÊM RECURSOS PARA ESTUDAR EM OUTROS CENTROS MAIS EVOLUIDOS!" (FOLHA DO OESTE, 1968, p.1).

Os anúncios na primeira página do jornal: "Desperta Consciência Coletiva Guarapuava" (FOLHA DO OESTE, 1968, p.1) a mesma redação continua em seu apelo aos cidadãos guarapuavanos:

Eis, pois concidadãos guarapuavanos, o atual e maior problema que nos depara e está a exigir nossa imediata ação. Se ficarmos no "comodismo" de esperar pela ação somente do poder público, via de regra bem intencionado, porém ás vezes impotente ante a magnitude dos problemas, estaremos cometendo o crime de compelir nossos filhos, nossa juventude atual, a constituir amanhã, uma geração trôpega e semi analfabeta! [...] deve o povo guarapuavano, avocá-lo a si o dever de pô-lo em pauta na ordem de suas reivindicações maiores, criando em torno dele o halo de uma robusta CONSCIÊNCIA COLETIVA necessária e indispensável ao êxito de sua urgente concretização. (FOLHA DO OESTE, 1968, p.1) caixa alta no original.

O apelo para arrecadação de fundos também se fez presente entre os argumentos na tentativa de provar que a iniciativa era possível de ser concretizada: 
[...] um vigoroso e espontâneo movimento nesse sentido, catalisando para robustecê-lo o apreço e adesão de todas as forças vivas de nossa comunidade: Clero e Autoridades, Representações Parlamentares, Associações de Classe, Entidades Sociais, Imprensa, Rádio e etc...., que conjugando esforços com sua Juventude, inclusive através de campanhas de contribuição popular para formação de fundo econômico, que somados ao de origem pública já existentes para esse fim, poderia aparelhar um edifício para funcionamento de Cursos Superiores. (FOLHA DO OESTE, 1968, p.1).

O problema estava posto em discussão e mais argumentos iam surgindo para sustentar a necessidade de implantação do ensino superior na cidade: "Circula uma versão local segundo a qual Guarapuava presentemente não pode ter Faculdade visto o reduzido número de matrícula no $3^{\circ}$ Ano do Curso Científico" (FOLHA DO OESTE, p.1, em abril de 1968). Se a informação não pode ser negada, explicava-se que falta de matrículas davase,justamente, devido à falta de uma Faculdade na cidade, visto que o curso científico preparava para o vestibular e ingresso no ensino superior. Os alunos guarapuavanos que dispunham de recursos ao concluírem o ginásio ou os primeiros anos do curso científico se transferiam para centros estudantis mais bem aparelhados, para poderem cursar o $3^{\circ}$ ano do científico e poderem, concomitante, realizar os cursos preparatórios para enfrentarem os vestibulares. Outra porcentagem de alunos, em virtude, da não existência de faculdade na cidade, optava pelo Curso de Comércio ou o Curso Contábil que, uma vez concluído, davalhes o direito de igualmente acessar o ensino superior, além de habilitá-los a exercer uma atividade profissional, o que, nesse caso, parecia mais atraente para a realidade da cidade de Guarapuava na década de 1960.

O corpo docente da educação básica existente na cidade, em sua quase totalidade professores sem graduação, procurou envolver a comunidade escolar, utilizando-se da única rádio da cidade a Rádio Difusora, na qual se pedia a união de todos pela causa do ensino superior. O professorado se uniu por conta da oportunidade de obterem uma titulação.

O Sr. Alcides Ragazzi nos relata que a congregação dos padres salvatorianos, junto com a sociedade local, reuniu-se para pensar naquele espaço físico e naquelas instalações, já que fora descartada a possibilidade da escola no modelo de internato pelos padres. As instalações foram avaliadas como adequadas e como já havia por meio dos jornais discursos a favor de uma instituição de ensino superior em Guarapuava e também discursos políticos desejando e reivindicando para Guarapuava uma instituição de ensino superior, criaram-se as condições para um empenho mais efetivo no sentido de realizar, naquele momento, o ensino superior em Guarapuava.

O Sr. Ragazzi que foi apresentado junto à Assembleia Legislativa do Paraná um projeto no qual se manifestava a vontade de criar em Guarapuava uma instituição de ensino superior. A prefeitura conseguiu sensibilizar os deputados que assinaram uma moção, uma exposição de motivos em favor da reivindicação. Conseguido o apoio na Assembleia Legislativa, logo em Guarapuava, passa-se a trabalhar no processo de criação, que aconteceu da seguinte forma:

O Padre Contini que era o diretor do Ginásio Santa Cruz e eu na época Padre Egídio constituímos uma comissão, um grupo de serviço composto por mim, pelo então Padre Contini, pelo professor Nelson Zagorski e pelo professor Newton Felipe Albach. Nós elaboramos todo o processo para a criação da Faculdade e protocolamos o processo, para que o mesmo recebesse parecer técnico e a aprovação.[...] Eu ajudei particularmente na 
parte burocrática e política eu viajava bastante, para cumprir a diligencias que havia, que tínhamos que cumprir. (RAGAZZI, 2013)

O então Secretário de Interior e Justiça interino, o Senhor João de Mattos Leão encaminhou ao Governador do Estado Paulo Pimentel a moção, exposição de motivos em favor do ensino superior em Guarapuava, o que foi aprovado. Depois disso, determinou ao secretário de educação que se criasse a Fundação Faculdade de Filosofia Ciências e Letras de Guarapuava com inicialmente quatro cursos de licenciatura. Seriam inicialmente as licenciaturas de História, Geografia, Letras e Pedagogia. Aconteceu uma mudança por conta de uma reivindicação dos educadores de Guarapuava e região. Os professores em questão pediram a troca do curso de Pedagogia pelo curso de Matemática, argumentando pela escassez dos docentes especificamente nessa área da educação e que o curso Normal supriria um pouco as necessidades da área da Pedagogia sendo assim, antes do início do seu funcionamento foi realizada a troca. Em 02 de março de 1970 começa a funcionar a Faculdade de Filosofia, Ciências e Letras de Guarapuava, a FAFIG com seus quatro cursos de licenciatura, na tentativa de formar professores para centro-oeste do Paraná e região.

$\mathrm{O}$ ex- sacerdote esteve junto aos maiores interessados no assunto, sendo que a grande maioria era constituída de professores. Por essa razão, ele considera esses trabalhadores da educação como os principais responsáveis pela fundação da Instituição. Assim ele expõe:

\begin{abstract}
A vontade sempre foi de fundar uma Escola de Agronomia. Daí entra a manifestação pública dos professores e das professoras, que constituíram uma movimentação docente em favor de uma faculdade que formasse professores. Eu, Alcides Ragazzi, na época Padre Egídio, pensava por ser uma região de muita pecuária e agricultura, que a instituição pudesse ser uma Escola de Agronomia, mas esbarramos em muitos problemas, como os laboratórios, que eram muito caros para se adquirir, e, em como montar o corpo docente, precisavam vir todos de fora, então naquele, momento, não era viável Agronomia e era mais necessário a Faculdade de Filosofia. (RAGAZZI, 2013)
\end{abstract}

No entanto, com o levantamento junto aos professores e profissionais da educação da cidade de Guarapuava, no período dos anos finais da década de 1960, os quais foram a favor de se ter na cidade uma faculdade de filosofia, uma vez que havia uma necessidade do professorado de se profissionalizar, devido as reformas de ensino iniciadas nos anos de 1968 e 1969 em que se exigia que os professores para lecionarem no ensino secundário, possuíssem licenciatura nas áreas afins, por isso consideraram a opção pela faculdade de filosofia, muito mais que uma necessidade, mais sim, algo de extrema urgência. O Sr. Ragazzi relata que à época, ouviu os profissionais da Inspetoria de Educação Estadual, além de conversar com os professores à ela subordinados e representantes da Secretaria de Educação do Município. Com isso, levantou a "estatística local" que deixou clara a necessidade de formar professores antes de qualquer outra coisa.

Em entrevista concedida dia 08 de outubro de 2013, a ex-aluna e, depois, exprofessora da Instituição Gracita Gruber Marcondes, endossou as afirmações de Ragazzi. Ela explica que, desde a década de 1950, já havia entre os docentes da cidade uma manifestação no sentido de reivindicação de uma instituição de ensino superior para formar professores. Os professores se movimentavam em torno da questão, pois a grande maioria não possuía curso superior. Marcondes destaca que as reivindicações ganharam força quando a secretaria da educação começou a proibir a contratação de professores sem graduação para lecionar no ensino secundário. À época, ainda de acordo com Marcondes, 
com exceção de alguns professores advindos de outras áreas de ensino superior como Direito, Odontologia, Química para atuarem no magistério em áreas coerentes com a sua formação, havia os professores normalistas que cursaram a, então Escola Normal e outros que não possuíam nenhuma dessas formações. Eles apenas concluíram seus estudos básicos iniciais e realizavam exames de admissão e treinamentos oferecidos pelas inspetorias de ensino do Estado.

Em 1968, o Ministério de Educação realizou alguns cursos, em seguida, aplicava-se exame de suficiência, que permitiam aos docentes lecionarem no ensino secundário, mediante certificação. Guarapuava enviou quase todos os professores para fazer esse curso, de todas as áreas. Explica Marcondes que esse acontecimento também ajudou nas reivindicações em prol da faculdade de filosofia e seus cursos de licenciatura para formar professores. Existiram passeatas organizadas por professores, que procuravam envolver os alunos e os pais na conscientização dessa necessidade. Nas palavras da historiadora: "Nós organizamos as passeatas em prol da faculdade, pois nós estávamos sentido na carne a falta, porque até então nós estávamos garantidos com aquele exame de suficiência, mas a gente temia que dali um pouquinho eles tirassem esse nosso direito".

Os marcos do depoimento de Marcondes correspondem às datas de extinção da CADES. Conforme Pinto (2008, p.7), o processo de encerramento das atividades dessa Campanha de Aperfeiçoamento e Difusão do Ensino Secundário, teria ocorrido em 1969 com o Decreto-Lei $n^{\circ} 900$, de 29 de setembro de 1969. Com a data pode-se inferir ao que explanou Marcondes ao relatar a insegurança dos professores no que tange à validade da certificação conseguida, ao realizarem o exame de suficiência em 1968.

Percebemos, então,que as reivindicações em torno do processo de construção da FAFIG, esteve diretamente ligada aos setores sociais médios da população local envolvendo profissionais da educação, o poder eclesiástico e político da cidade.

\section{Considerações finais}

Percebemos no bojo das transformações, políticas, econômicas, sociais e culturais no transcorrer das décadas de 1960 e 1970, que as reformas educacionais estavam presentes nos mais variados níveis de ensino, chegando ao superior com a Lei 5.540/68. Notamos que o processo de criação da FAFIG esteve diretamente conectado às transformações da sociedade brasileira e suas necessidades imediatas. Além disso, a FAFIG também lidou com problemas especificamente locais ao encetar discursos e defesas que seu papel seria a formação de professores. Em que pese à urgência regional dessa questão, há que se verificar os impactos que essa instituição, concretamente, gerou no que tange à resolução dos problemas sociais. Problemas sociais, em última instância, visto como gerados pelas mazelas educacionais que teriam uma de suas principais facetas (a falta de professores) atacadas pela expansão do ensino superior na região. Nesse sentido, a consequência direta de uma necessidade concreta fez com que a união de forças locais, adicionada às demandas vindas de toda a estrutura social oferecessem o leque de possibilidades para o processo para a instalação da FAFIG.

Por isso, é interessante verificarmos o modo como essa especificidade é devedora das necessidades postas pelas transformações socioeconômicas que aconteciam em outros âmbitos. O capitalismo internacional adentrava o país com as multinacionais, tratando de encaixar o Brasil ao modelo de capital associado e dependente e a nossa educação sofria a influência direta advindas desse modelo econômico adotado durante o período vigente da Ditadura Militar. 
Se a criação da FAFIG amarra-se com o processo de formação de professores da região de Guarapuava e com dilemas semelhantes sentidos em outras regiões do país e que tocam a história educacional do período em tela, surge como problemática a averiguação dos impactos que ela teve na educação da região, nos anos que se seguiram. Ao não ocupar-se, diretamente, dessa questão, avaliamos que um dos resultados das investigações que agora encerramos, é endossar a necessidade de novos estudos sobre essa instituição e sua relação com os problemas e possibilidades educacionais da cidade de Guarapuava.

\section{Referências}

Fontes primárias

FOLHA DO OESTE, 1960, p.8, No 311 de 10 de abril de 1960. ANO VII da $3^{\text {a }}$ fase.

FOLHA DO OESTE, 1962, p.1 e 8, Nº1292 de 18 de março. ANO XXV.

FOLHA DO OESTE, 1962 p. 1, No 1293 de 25 de março. ANO XXV.

FOLHA DO OESTE, 1962, p.8, № 1293 de 25 de março. ANO XXV.

FOLHA DO OESTE, 1967, p. 2, No 1474, de 11 de junho. ANO 30.

FOLHA DO OESTE, 1968, p.1, No 1513, de 21 de abril. ANO 31.

FOLHA DO OESTE, 1968, p.1, No 1513, de 21 de abril. ANO 31.

FOLHA DO OESTE, 1968, p.1, No 1516, de 12 de maio. ANO 31.

FOLHA DO OESTE, 1968, p.6, No 1516, de 12 de maio. ANO 31.

Entrevistas/depoimentos

MARCONDES, G. G. Depoimento concedido a autora em 08/10/2014.

RAGAZZI, A. Depoimento concedido a autora em 03/09/2013.

Livros, artigos, capítulos de livros, dissertações e teses.

AMARAL, M.L.; HEROLD JR C. Representações sobre a relação entre educação e modernização em Guarapuava-PR entre 1930 e 1960. Revista HISTEDBR On-line, Campinas n.38, p. 36-48, jun.2010. Disponível em:< www.histedbr.fae.unicamp.br/revista/edicoes/38/art04_38.pdf

FILLOS, L.M. A Matemática em Irati (PR): História e Memórias de Professores. Anais do IX Seminário Nacional de História da Matemática. 2008. USP Acesso em 12/11/2013.

www.each.usp.br/ixsnhm/.../1_Fillos_L_M_Matemática_em_Irati(PR).pd. 
MARCONDES, G. G. et al. FAFIG: 15 anos de história. Guarapuava: FAFIG, 1985.

. Duzentos anos de uma caminhada histórica. Guarapuava. 2010.

MARX, K.; ENGELS F. A Ideologia Alemã: crítica da mais recente filosofia alemã. Tradução: Rubens Enderle, Nélio Scheneider e Luciano Cavini Martorano. São Paulo: Boitempo, 2007.

PINTO, D. C. Campanha de aperfeiçoamento e difusão do ensino secundário: uma campanha bem sucedida? Anais do congresso SBHE. Aracaju. SE, 2008.

SANTOS, J. C.; SHREIBER, C. Colégio Agrícola Estadual “Arlindo Ribeiro" em Guarapuava/PR. Histedbr. SP. UNICAMP. 2011. Acesso em 31/07/2013. www.histedbr.fae.unicamp.br/acer_histedbr/jornada/.../Chs58Lru.doc

SCHELBAUER, A. R.; ARAÚJO, J. C. S. História da educação pela imprensa. Campinas: Alínea, 2007.

SILVA, Walderez Pohl da. Entre Lustosa e João do Planalto - A arte política na cidade de Guarapuava (1930-1970). Rio de janeiro. UFF. (TESE de doutorado) 2008. Acesso em 17/11/2013 www.historia.uff.br/stricto/teses/Tese-2008 SILVA Walderez Pohl da-S

THOMPSON, P. A voz do passado - História Oral. Rio de Janeiro: Paz e Terra, 1992.

FONTES IMPRESSAS (Centro de Documentação e Memória de Guarapuava - Arquivo Histórico da UNICENTRO) - ( Casa Benjamim Teixeira) - O Jornal Folha do Oeste possui uma nomenclatura diferente em sua numeração por conta da administração jornalística conforme a fase em que se encontrava o jornal.

\section{Notas}

\footnotetext{
${ }^{1}$ Mestre em Educação - Universidade Federal do Paraná- UFPR

${ }^{2}$ Professor Adjunto - Departamento de Educação Física - UEM carlosherold@ @otmail.com

${ }^{3}$ maneirismo (uso excessivo de determinados procedimentos, em arte e literatura - modos afetados de falar e gesticular) ortografia de acordo com o documento.
}

Recebido: fevereiro/14 Aprovado: julho/14 